\title{
Endoscopic Treatment for Early Gastric Cancer
}

\author{
Sang Gyun Kim \\ Department of Internal Medicine and Liver Research Institute, Seoul National University College of Medicine, Seoul, Korea
}

\begin{abstract}
Endoscopic resection has been accepted as a curative modality for early gastric cancer (EGC). Since conventional endoscopic mucosal resection (EMR) has been introduced, many improvements in endoscopic accessories and techniques have been achieved. Recently, endoscopic submucosal dissection (ESD) using various electrosurgical knives has been performed for complete resection of EGC and enables complete resection of EGC, which is difficult to completely resect in the era of conventional EMR. Currently, ESD is accepted as the standard method for endoscopic resection of EGC in indicated cases. In this review, the history of endoscopic treatment for EGC, overall ESD procedures, and indications and clinical results of endoscopic treatment will be presented.
\end{abstract}

Key Words: Endoscopic submucosal dissection, Early gastric cancer, Indication

\section{Introduction}

Endoscopic resection has been accepted as a curative modality for early gastric cancer (EGC) in indication of complete resection without the risk of metastasis. Since conventional endoscopic mucosal resection (EMR) has been introduced from 1984, many improvements of endoscopic accessories and techniques have been achieved.(1) Recently, endoscopic submucosal dissection (ESD) using various electrosurgical knives has been performed for complete resection of EGC, and enables complete resection of EGC which had many technical difficulties in complete resection in the era of conventional EMR.

As the proportion of EGC has been increasing by early detection with national cancer screening program in Korea (biannual upper endoscopy or barium study for all population over age of 40), endoscopic treatment for EGC has been expanded with the

Correspondence to: Sang Gyun Kim

Department of Internal Medicine and Liver Research Institute, Seoul National University College of Medicine, 101 Daehak-ro, Jongno-gu, Seoul 110-799, Korea

Tel: +82-2-740-8112, Fax: +82-2-743-6701

E-mail: harley1333@hanmail.net

Received August 16, 2011

Revised August 20, 2011

Accepted August 22, 2011 progress of endoscopic technique and accessories. In this review, endoscopic resection for EGC would be presented as the history, indication, risk of lymph node metastasis and clinical results.

\section{History of Endoscopic Resection for EGC}

Since endoscopic resection with electrosurgical snare has been introduced for colorectal polyp in 1973, endoscopic resection has been performed for polypoid-type EGC as curative intent. In 1984, strip biopsy method has been developed for resection of flat-type EGC. In this method, the flat lesion is changed to polypoid lesion by submucosal injection of mixture of normal saline with diluted epinephrine, and resected by grasper forcep and electrosurgical snare through 2-channel endoscope. Although this method had advantages of easy technique, short procedure time and less complication, complete resection rate was around 50 70\%, which was lower than expected for large-sized or depressed-type EGC.(2)

In 1988, EMR-precutting method has been developed, in which after hypertonic saline with diluted epinephrine is injected to submucosal layer around the lesion, circumferential incision around the lesion with needle knife and final resection of the lesion is performed with electrosurgical snare. This method has enabled complete en-bloc resection rather than conventional EMR, but

(c) This is an open-access article distributed under the terms of the Creative Commons Attribution Non-Commercial License (http://creativecommons.org/ licenses/by-nc/3.0) which permits unrestricted noncommercial use, distribution, and reproduction in any medium, provided the original work is properly cited 
risk of perforation was higher during the circumferential incision, which necessitated higher expertise. Moreover, en-bloc complete resection was still difficult for large-sized or depressed-type EGC.

In 1992, EMR by the cap-fitted method (EMR-C) has been developed, in which en-bloc resection was performed with electrosurgical snare after suction of the lesion by cap-fitted endoscope.(3) Although this method was easier and safer than conventional EMR for en-bloc resection of small-sized EGC, enbloc complete resection was still impossible for larger-sized EGC than diameter of the cap.(4)

To overcome the disadvantages of previous methods, ESD has been developed in late 1990's. In ESD, circumferential incision and direct dissection of submucosal layer of EGC has been possible with various knives, which has enabled en-bloc complete resection even in large-sized or depressed-type EGC. Various knives have been introduced for safe and complete ESD for EGC, and have different advantages/disadvantages according to the lesion. In present, insulation-tipped (IT), triangle-tipped (TT), flex, hook, fork, flush and splash knives are available for ESD. midazolam or propofol. With a standard single-channel endoscope, thorough examination is mandatory for the evaluation of whole stomach including the target lesion. After the chromo-endoscopic observation with indigo carmine, marking dots $5 \mathrm{~mm}$ outside the tumor margin are made using a conventional needle knife with a forced $20 \mathrm{~W}$ coagulation current (VIO 300D; Erbe, Tübingen, Germany) or argon plasma coagulation. Then a mixture of normal saline and indigo carmine with diluted epinephrine $(1: 100,000)$ is injected into the submucosal layer along with the marking dots to make the submucosal cushion beneath the lesion. After a small initial incision is made with the needle knife, a circumferential mucosal incision is made around the marking spots, and the submucosal layer is dissected using various knives in $80 \mathrm{~W}$ endocut mode. Hemostasis is usually performed for bleeding spots or visible vessels with a coagrasper or argon plasma coagulation. After ESD, the patients is administered proton pump inhibitors intravenously at the day of procedure and then orally for four weeks for the healing of iatrogenic ulcer, pain control and prevention of perforation or post-procedural bleeding.

\section{Procedure of ESD}

ESD is usually performed under sedation with intravenous

\section{Selection of Knife}

Knife is divided into blade- and tip-type according to resection
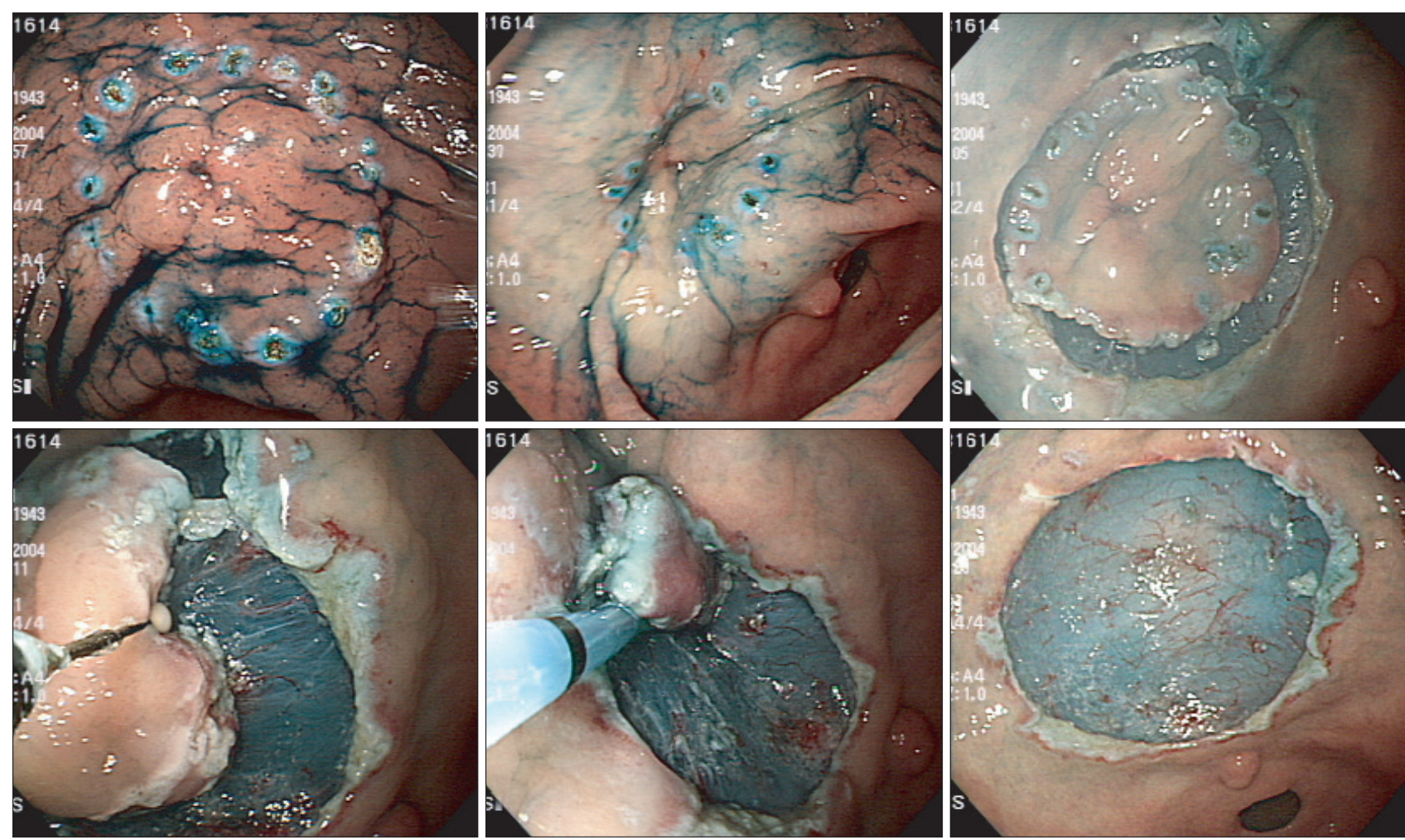

Fig. 1. ESD for EGC from marking, submucosal injection, circumferential incision to submucosal dissection. ESD = endoscopic submucosal dissection; EGC = early gastric cancer. 
site. Blade-type; needle, IT and TT knife, Tip-type; flex, hook, fork, flush and splash knife.

Needle knife is usually used in sphincterotomy during endoscopic retrograde cholangiopancreatography, and generates both cutting and coagulation current by electrosurgical unit. It has been used in submucosal dissection for the first time as a simple type.

At first, needle knife is used in marking around the lesion with coagulation current by adjustment of needle length up to $6 \mathrm{~mm}$. Long needle has the risk of bleeding or perforation by attachment of needle to coagulated mucosa. Circumferential incision should be performed with cutting current by step by step for the prevention of perforation. In submucosal dissection, caution should be kept whether dissection is accurately made in submucosal layer.

Needle knife usually necessitates transparent cap at the tip of endoscope for prevention of perforation. Although needle knife has a high speed in resection, longer time can be needed in a beginner for the risk of perforation. Nowadays, needle knife is used for making the hole at the beginning rather than circumferential incision or submucosal dissection.

IT knife has an insulated tip of $2.2 \mathrm{~mm}$ in diameter for the prevention of perforation.(5) Since Hosokawa from Japan has introduced in 1996, IT knife has been used in ESD. It can be used in circumferential incision and submucosal dissection, even in hemostasis of minor bleeding with coagulation current.

After making the incision hole with needle knife, circumferential incision around the lesion is made with IT knife. Insulated tip has an advantage of prevention of perforation even in dead angle.
Pull-method with angle of 45 degree from distant part is favorable in incision. In submucosal dissection, full utilization of blade with insulated tip has advantages of shorter procedure time with fast dissection and prevention of perforation even in dead angle. Pushmethod from nearest part or pull-method from distant part is favorable in submucosal dissection.

The lesion in perpendicular plane such as fundus or greater curvature of upper body is limited in resection with IT knife, and perforation can occur even with insulated tip by whole-blade resection. Although easy procedure and short procedure time can be advantages to experts, unexpected perforation may be a disadvantage to beginners.(6)

TT knife has a triangle diathermic disc at the tip of 4.5 $\mathrm{mm}$ in length, and can be used in marking around the lesion,

Table 1. Expanded indication of endoscopic treatment for early gastric cancer

\begin{tabular}{|c|c|c|c|c|c|c|}
\hline \multirow{5}{*}{ Histology } & \multicolumn{6}{|c|}{ Depth } \\
\hline & \multicolumn{4}{|c|}{ m-cancer } & \multicolumn{2}{|c|}{ sm-cancer } \\
\hline & \multicolumn{2}{|c|}{ Ulcer (-) } & \multicolumn{2}{|c|}{ Ulcer (+) } & \multirow{3}{*}{$\begin{array}{l}\leq \mathrm{sm} 1 \\
\begin{array}{l}\leq 30 \\
\mathrm{~mm}\end{array}\end{array}$} & \multirow{3}{*}{$\begin{array}{c}>\text { sm } \\
\begin{array}{c}\text { Any } \\
\text { size }\end{array}\end{array}$} \\
\hline & $\leq 20$ & $>20$ & $\leq 30$ & $>30$ & & \\
\hline & $\mathrm{mm}$ & $\mathrm{mm}$ & $\mathrm{mm}$ & $\mathrm{mm}$ & & \\
\hline Differentiated & $\mathrm{A}^{*}$ & $\mathrm{~B}^{\dagger}$ & B & $\mathrm{D}^{\S}$ & B & $\mathrm{D}$ \\
\hline Undifferentiated & $C^{\ddagger}$ & $\mathrm{D}$ & $\mathrm{D}$ & $\mathrm{D}$ & $\mathrm{D}$ & $\mathrm{D}$ \\
\hline
\end{tabular}

${ }^{*}$ Definite indication by guideline; ${ }^{\dagger}$ Expanded indication; ${ }^{*}$ Surgery, but need for more consideration; ${ }^{\S}$ Surgery. $\mathrm{m}=$ mucosa; $\mathrm{sm}=$ submucosa

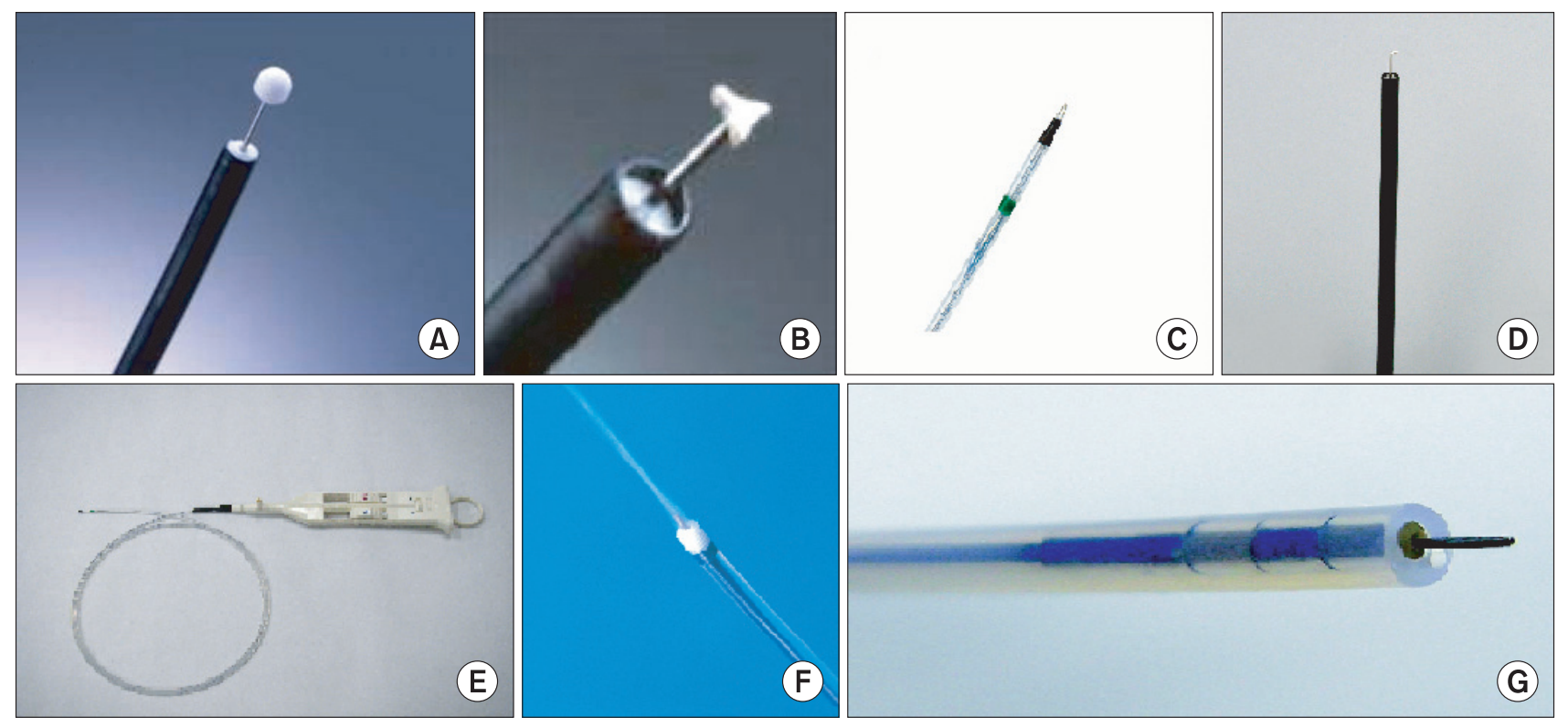

Fig. 2. Various knives used in ESD. (A) IT knife, (B) TT knife, (C) Flex knife, (D) Hook knife, (E) Fork knife, (F) Flush knife, (G) Splash knife. ESD $=$ endoscopic submucosal dissection; $\mathrm{IT}$ = insulation-tipped; TT = triangle-tipped. 
Endoscopic Treatment for Early Gastric Cancer

circumferential incision and submucosal dissection, even in hemostasis of minor bleeding with coagulation current.

After hole-making with TT knife alone, circumferential incision around the lesion is performed with pull-method from distant part. In submucosal dissection, pull-method with diathermic disc is performed from distant part by step by step. Apart from IT knife, dissection with diathermic disc alone needs longer procedure time. The risk of perforation in dead angle can be reduced by fitting transparent cap which enables direct vision of dissection.

Flex knife has a tip of soft semicircular snare, and can be used in marking around the lesion, circumferential incision and submucosal dissection, even in hemostasis of minor bleeding with coagulation current.(7) Soft semicircular snare is contained in soft plastic case, and can be adjusted in length.

After marking, circumferential incision around the lesion is performed with $1 \mathrm{~mm}$ in length from distant part. Push-method is used with 1 1.5 mm in length from proximal part in submucosal dissection. The risk of perforation is minimized because of bending of knife with soft nature even in jerky movement. Submucosal dissection by step by step has longer procedure time, and dead angle necessitates fitting transparent cap to prevent perforation. But accurate dissection can be performed by direct vision of dissected submucosa. Also, flex knife with soft nature enables dissection in every direction, even in perpendicular plane. Fixed maintenance of length of knife is indispensible to prevent unexpected perforation in jerky movement.

Hook knife has a hooked tip with $4.5 \mathrm{~mm}$ long and $1.3 \mathrm{~mm}$ in transverse, and can be used in marking around the lesion, circumferential incision and submucosal dissection, even in hemostasis of minor bleeding with coagulation current.(8) The tip is rotatable in 360 degree to dissect in every direction. Methods of marking, submucosal injection, circumferential incision and submucosal dissection are same as TT knife.

Fork knife developed in Korea has an advantage of marking, incision, dissection, hemostasis, injection and irrigation by one knife without changing accessories.(9) Fork knife is composed of needle used in marking and incision and fork used in injection and dissection, which can be handled separately. Methods of marking, submucosal injection, circumferential incision and submucosal dissection are same as flush knife. Major advantage of fork knife is time-saving because of total procedure in one knife without changing accessories. But, needle knife has a risk of perforation during incision, and difficulties in procedure in case of inaccessible location. Submucosal dissection with fork by step by step has longer procedure time, and dead angle necessitates fitting transparent cap to prevent perforation. But accurate dissection can be performed by direct vision of dissected submucosa.

Flush knife has an advantage of marking, incision, dissection, hemostasis, injection and irrigation by one needle-type without changing accessories.(10) Methods of marking, submucosal injection, circumferential incision and submucosal dissection are same as fork knife.

Splash knife has an advantage of marking, incision, dissection, hemostasis, injection and irrigation by one needle-type without changing accessories.(11) Knife is $2.5 \mathrm{~mm}$ long and controllable. Methods of marking, submucosal injection, circumferential incision and submucosal dissection are same as flush knife.

Selection of knife is dependent on the lesion by each characteristic. Although most procedure is performed with one knife, various knives can be utilized for accurate and safe procedure by case by case. Decision factors of knife are location, morphology, size of the lesion and type of procedure. But most of all, familiarity to operator is most important. That is, most important factor of selection of knife is easiness and familiarity to operator.

In cases of stomach, the lesion of greater curvature of high body, fundus and angle is difficult to manage. The lesion of greater curvature of high body and fundus is perpendicular with knife, and is difficult to manage with IT and TT knife. On the other hand, the lesion of angle can be difficult to approach and manage with flex, fork, flush and splash knife which should contact the lesion to dissect because of excessive air inflation during procedure. IT knife has an advantage in management of inaccessible lesion.

Submucosal dissection can be difficult for excessive fibrosis in the lesion with submucosal fibrosis or underlying scar formation. IT knife has an advantage of wide dissection plane and shorter procedure time in experts. To shorten the procedure time for large lesion, IT knife has an advantage of wide dissection plane, and fork, flush or splash knife has an advantage of total procedure with one knife to shorten the procedure time.

\section{Conventional Indication of Endoscopic Resection for EGC}

As the technical progress has achieved from conventional EMR to ESD, most of limiting factors in complete en-bloc resection have been overcome irrespective of size, shape or location of the tumor, which has resulted in the expansion of the indication of endoscopic resection for EGC. Moreover, ESD has been substituted for surgical 
resection with increased portion of old age and $\mathrm{co}^{-}$-morbidity and importance of postoperative quality of life.

Prior to expansion of indication of endoscopic resection for $\mathrm{EGC}$, the prerequisite is to maintain the quality of life without the sacrifice of survival, which means that the expanded indication should only include EGC without lymph node or distant metastasis, enable complete en-bloc resection without serious complication, and ensure long-term survival not inferior to surgical resection. Therefore, the expansion of indication of endoscopic resection for EGC has a pitfall in the possibility of sacrifice of survival in the setting of insufficient results of long-term survival after endoscopic resection for EGC.

Conventional indication of endoscopic resection for EGC is as follows, 1) differentiated adenocarcinoma confined to mucosa, 2) elevated type $\leq 2 \mathrm{~cm}$, 3) depressed type without ulcer $\leq 1$ $\mathrm{cm}$. In this indication, the tumor rarely metastasizes to regional lymph node or distant organ and can be resected endoscopically with negligible risk of recurrence.(12) Beyond the conventional indication, the tumor in most cases could not be resected completely by conventional EMR with low cure rate in spite of the possibility of candidates of endoscopic resection. Therefore, indication of endoscopic resection was confined to small-sized, superficial tumor which could be resected with en-bloc fashion in the era of conventional EMR.

In the era of ESD, most limiting factors have been overcome in complete resection, and the indication of ESD is decided by the risk factors of lymph node or distant metastasis.(13) Although the risk factors of lymph node or distant metastasis are generally accepted as 1) tumor size, 2) differentiation of tumor, 3) invasion depth of tumor, and 4) angiolymphatic invasion of tumor, definite indications of endoscopic resection for EGC are variable according to the studies because of 1) different indication according to studies, 2) retrospective manner, 3) small sample size, and 4) short-term follow-up period.

\section{Risk Factors of Lymph Node Metastasis in EGC}

Although the risk of lymph node metastasis in EGC increases with tumor size, depth of tumor invasion and undifferentiated histology, definite indication of endoscopic resection for EGC is variable according to the studies, and the standard indication is not established.(14)

In a retrospective study with surgically-resected cases with
EGC, the expanded indication of endoscopic resection for EGC was proposed with no evidence of lymph node metastasis in; 1) differentiated mucosal cancer without ulcer irrespective of size, 2) differentiated mucosal cancer with ulcer $\leq 3 \mathrm{~cm}$, 3) undifferentiated mucosal cancer $\leq 2 \mathrm{~cm}, 4)$ differentiated submucosal cancer $\leq 500$ $\mu \mathrm{m}$ depth of invasion (sm1) $\leq 3 \mathrm{~cm}$ in size without angiolymphatic invasion. $(15,16)$

On the other hand, lymph node metastasis was found in 4.5\% of mucosal cancer and $22.8 \%$ of submucosal cancer in another retrospective study with 2,173 surgically-resected cases of EGC. (17) Of those, lymph node metastasis was found in some of differentiated mucosal cancer without ulcer and $2 \mathrm{~cm}$ differentiated mucosal cancer with ulcer, which explains that the risk of lymph node metastasis is not negligible even in the expanded indication of endoscopic resection for EGC.

Although undifferentiated histology is not considered to be the indication of endoscopic resection with higher risk of lymph node metastasis rather than differentiated histology, some portion may be the indication of endoscopic resection with negligible risk of lymph node metastasis. In a retrospective study with 591 surgicallyresected cases of undifferentiated EGC, there was no lymph node metastasis in 119 cases with tumor size less than $2.5 \mathrm{~cm}$, confined to mucosa or sm1, and without angiolymphatic invasion, which might be the expanded indication of endoscopic resection.(18)

In the expanded indication of endoscopic resection for EGC, the pre-evaluation of regional lymph node and distant metastasis is very important with the increment of risk of metastasis.(19) As the risk factors of lymph node metastasis such as accurate tumor size, differentiation, depth of tumor invasion and angiolymphatic invasion cannot be known prior to endoscopic or surgical resection, the risk of lymph node metastasis is restricted to assumption in pretreatment staging. Although endoscopic ultrasonography, computerized tomography, positron emission tomography have been used in cancer staging, diagnostic accuracy for lymph node or distant metastasis varies in 50 80\%. To expand the indication of endoscopic resection for EGC, new diagnostic modality is mandatory for the evaluation of lymph node metastasis prior to definitive treatment.

Most of all, long-term survival after endoscopic resection should be proven to be not inferior to that after surgical resection to expand the indication of endoscopic resection for EGC. Although conventional EMR for conventional indication have shown longterm survival not inferior to surgical resection in completelyresected cases, long-term survival after ESD has not been 
established without sufficient data. Long-term prospective study is warranted for long-term survival after ESD for EGC.

\section{Standardization of Risk Factors of Lymph Node Metastasis in EGC}

Risk factors of lymph node metastasis in EGC are known to be tumor size, depth of tumor invasion, differentiation and angiolymphatic invasion, which have variable criteria according to the studies.(20) In tumor size, discrepancy may exist between surgically-resected and endoscopically-resected specimen. In surgical resection, the tumor size is measured after fixation with formalin, which may be reduced by shrinkage. On the other hand, the specimen is creased and fixed with pin in endoscopic resection, which may be exaggerated in size. Therefore, the study with endoscopically-resected cases may show the result of expanded indication in tumor size rather than the study with surgicallyresected cases.

Depth of tumor invasion can be confused in endoscopicallyresected cases. On the contrary to surgically-resected specimen, endoscopically-resected specimen does not include all layers of stomach but mucosa and partial submucosa. In the cases of submucosal invasion of tumor, accurate depth of tumor invasion cannot be verified in endoscopically-resected specimen because of lack of muscularis propria which can be the standard of interpretation. Although submucosal layer is divided by 3 with 500 $\mu \mathrm{m}$, depth of tumor invasion can be much influenced by tissue preparation after endoscopic resection.

Intra- or inter-observer variation among pathologists can exist in the evaluation of differentiation of tumor. High grade dysplasia vs. intraepithelial carcinoma is the main diagnostic problem among the pathologists. In favor of diagnosis of cancer rather than dysplasia, the indication of endoscopic resection may be expanded without the risk of lymph node metastasis. To standardize the risk of lymph node metastasis in EGC, the definition of size, depth of invasion and differentiation of tumor should be also standardized.

\section{Clinical Results of Endoscopic Resection for EGC}

Conventional EMR has shown unsatisfied results in terms of en-bloc complete resection, which lay from 53 74\% according to size, shape or location of EGC.(21) On the other hand, there is no limiting factor in ESD in terms of size, shape or location of
EGC. ESD enables en-bloc complete resection of larger-sized, depressed-type with submucosal fibrosis or difficult-located EGC. But ESD has disadvantages of longer procedure time and higher complication rate in terms of bleeding or perforation rather than conventional EMR, and necessitates a longer learning curve and expertise.(22) Therefore, conventional EMR can be still applied for small-sized, polypoid-type EGC rather than ESD regarding to risk and benefit.

Success rate of conventional EMR was influenced by tumor size, shape and location, and lowered in larger size than $2 \mathrm{~cm}$, depressed type and location of body lesser curvature or posterior wall.(23) On the contrary to conventional EMR, ESD has much improved the complete en-bloc resection rate. Although complete resection was achieved in $77.6 \%$ in a study with conventional EMR, another study with ESD in 1,000 cases has revealed enbloc resection rate of $95.3 \%$ and complete resection rate of $87.7 \%$. (24) From 2005 to 2010, a total of 690 cases with EGC were treated by ESD in Seoul National University Hospital. En-bloc resection was achieved in all cases, and complete resection rate was $94.2 \%$ in cases with expanded indication.

ESD has a higher risk of complication and longer procedure time than conventional EMR because of larger and deeper dissection. Bleeding and perforation are the most common complication of ESD, which can be reduced by expertise. In a study, major bleeding rate was $0.6 \%$ and perforation rate was $1.2 \%$ with mean procedure time of 47.8 minutes.(24) Most of bleeding and perforation can be managed by endoscopic hemostasis and clipping without surgical management.

After confirmation of complete resection of EGC at pathological mapping, periodic regular follow-up is performed to detect recurrence. 5-year recurrence free survival is estimated to $99 \%$ and overall survival is estimated to $95 \%$, which is comparable to surgical resection. Among 620 cases complete-treated by endoscopic resection in Seoul National University Hospital, 1 case of mortality by cardiovascular event was reported, and disease-free survival was $100 \%$ during follow-up. Considering the quality of life after treatment, ESD is a safe and effective treatment for EGC without sacrifice of survival compared to surgical resection.

\section{Recurrence after Endoscopic Resection for EGC}

Recurrence can be defined as the relapse of previous lesion, which includes local recurrence, synchronous or metachronous 
lesion, and distant metastasis. However, recurrence of narrow definition is remnant lesions at the site of treatment or metastatic lesions related with previous lesions treated.

Local recurrence is defined as remnant or relapsed cancer at same site after endoscopic resection during follow-up. ESD which enables en-bloc complete resection of larger tumor has reduced the rate of local recurrence of tumor compared with conventional EMR. Although local recurrence usually develops in a short-term period less than 6 months after initial resection, minute remnant cancer can grow up to gross mass after 1 year.

Local recurrence originates from remnant tumor in incompletely-resected site. In case of positive lateral resection margin at post-resection pathological mapping, remnant tumor around resection margin can grow with healing of iatrogenic ulcer after resection. On the contrary, remnant tumor can infiltrate submucosal or deeper layer in case of positive vertical resection margin in postresection pathological mapping.

Local recurrence can develop even after complete resection of tumor. Overlooked skipped tumor is not rare around main lesion in EGC, which can lead to local recurrence when the skipped lesion is not included in the resected specimen. To prevent overlooking the skipped lesion, sufficient resection margin should be guaranteed in case of ill-defined tumor margin.

If the post-resection pathological mapping has revealed the positive lateral resection margin, remnant tumor can exist around resection margin. All cases with positive lateral resection margin, however, have not remnant tumor. Mucosal cancers with positive lateral resection margin have been reported to have remnant tumor only in 5.8\%. Because cautery effect can ablate the remnant tumor around the circumferential incision during ESD, local recurrence can be prevented even in incomplete resection in terms of lateral margin. Therefore, frequent short-term endoscopic follow-up can be applied for detection of local recurrence in case of minute involvement of tumor in lateral resection margin.

When the local recurrence has developed in case of positive lateral resection margin, definitive treatment should be made for remnant cancer. If the remnant cancer is still confined to mucosa and the result of previous pathologic mapping has shown the negligible risk of lymph node metastasis in criteria of tumor size, differentiation and depth of tumor invasion, additional endoscopic resection can be applied to remnant cancer. However, secondary endoscopic resection could be more difficult in technique because of submucosal fibrosis after healing of iatrogenic ulcer. Sufficient resection margin should be ensured to prevent repetitive recurrence after additional endoscopic resection. Therefore, endoscopic ablation treatment with argon plasma coagulation (APC) can be applied at the site of repeated ESD as additional therapy. If the result of previous pathological mapping has revealed beyond the indication of endoscopic resection such as larger tumor size, positive angiolymphatic tumor invasion or undifferentiated histology, additional gastrectomy with conventional lymph node dissection should be made for the removal of risk of lymph node metastasis as well as remnant cancer.

Endoscopic ablation treatment can be applied to remnant tumor in endoscopically-unresectable and surgically-inoperable cases such as old age or significant co-morbidity. APC is useful for the ablation of superficial tumor and can be repeated with interval until complete resolution of remnant tumor.

When the local recurrence has developed in case of positive vertical resection margin, tumor can infiltrate submucosal or deeper layer because the method of ESD removes most of mucosal and submucosal layer. Therefore, additional gastrectomy and lymph node dissection should be made in case of positive vertical resection margin.

Synchronous lesion is defined as multiple tumors at diagnosis or newly-detected tumor within one year after initial resection. Oneyear interval is arbitrary because exact time of tumor initiation cannot be resolved. A tumor detected within one year after initial resection might exist at initial diagnosis because conventional endoscopy could not detect minute tumor less than $5 \mathrm{~mm}$ in size at initial diagnosis. Especially, tumor more than $5 \mathrm{~mm}$ in size within one year after initial resection could be exist even at initial diagnosis in viewpoint of doubling time of tumor. Metachronous tumor is defined as newly-developed tumor after one year of endoscopic resection. During follow-up after endoscopic resection, metachronous tumor develops at rate of 1 3\% per year.

The management of synchronous or metachronous tumor depends on status of respective tumor. If the tumor is indicated in endoscopic resection, ESD can be applied for complete resection. On the contrary, surgical resection should be applied in case beyond indication of endoscopic resection.

\section{Conclusions}

ESD has been a curative treatment modality of EGC in selective indications. The complete resection rate, long-term disease-free results and survival has been comparable to surgical treatment with the progress of endoscopic technique and accessories. After 
complete resection, regular follow-up examination is mandatory for the detection of metachronous tumor development.

\section{References}

1. Tada M, Shimada M, Murakami F, Karita M. Development of the strip off biopsy. Gastroenterol Endosc 1984;26:833-839.

2. Hirao M, Masuda K, Asanuma T, Naka H, Noda K, Matsuura $\mathrm{K}$, et al. Endoscopic resection of early gastric cancer and other tumors with local injection of hypertonic saline-epinephrine. Gastrointest Endosc 1988;34:264-269.

3. Inoue H, Takeshita K, Hori H, Muraoka Y, Yoneshima H, Endo M. Endoscopic mucosal resection with a cap-fitted panendoscope for esophagus, stomach, and colon mucosal lesions. Gastrointest Endosc 1993;39:58-62.

4. Akiyama M, Ota M, Nakajima H, Yamagata K, Munakata A. Endoscopic mucosal resection of gastric neoplasms using a ligating device. Gastrointest Endosc 1997;45:182-186.

5. Gotoda T, Kondo H, Ono H, Saito Y, Yamaguchi H, Saito D, et al. A new endoscopic mucosal resection procedure using an insulation-tipped electrosurgical knife for rectal flat lesions: report of two cases. Gastrointest Endosc 1999;50:560-563.

6. Ono H, Hasuike N, Inui T, Takizawa K, Ikehara H, Yamaguchi $\mathrm{Y}$, et al. Usefulness of a novel electrosurgical knife, the insulation-tipped diathermic knife-2, for endoscopic submucosal dissection of early gastric cancer. Gastric Cancer 2008;11:4752.

7. Kodashima S, Fujishiro M, Yahagi N, Kakushima N, Omata M. Endoscopic submucosal dissection using flexknife. J Clin Gastroenterol 2006;40:378-384.

8. Oyama T, Tomori A, Hotta K, Morita S, Kominato K, Tanaka $\mathrm{M}$, et al. Endoscopic submucosal dissection of early esophageal cancer. Clin Gastroenterol Hepatol 2005;3(7 Suppl 1):S67-70.

9. Kim HG, Cho JY, Bok GH, Cho WY, Kim WJ, Hong SJ, et al. A novel device for endoscopic submucosal dissection, the Fork knife. World J Gastroenterol 2008;14:6726-6732.

10. Yahagi N, Fujishiro M, Kakushima N, Kobayashi K, Hashimoto T, Oka M, et al. Endoscopic submucosal dissection for early gastric cancer using the tip of an electrosurgical snare (thin type). Dig Endosc 2004;16:34-38.

11. Fujishiro M, Kodashima S, Goto O, Ono S, Muraki Y, Kakushima N, et al. Successful en bloc resection of superficial esophageal cancer treated by endoscopic submucosal dissection with a splash needle. Endoscopy 2008;40(Suppl 2):E81-82.
12. Ono H, Kondo H, Gotoda T, Shirao K, Yamaguchi H, Saito D, et al. Endoscopic mucosal resection for treatment of early gastric cancer. Gut 2001;48:225-229.

13. Miyata M, Yokoyama Y, Okoyama N, Joh T, Seno K, Sasaki $\mathrm{M}$, et al. What are the appropriate indications for endoscopic mucosal resection for early gastric cancer? Analysis of 256 endoscopically resected lesions. Endoscopy 2000;32:773-778.

14. Abe N, Sugiyama M, Masaki T, Ueki H, Yanagida O, Mori T, et al. Predictive factors for lymph node metastasis of differentiated submucosally invasive gastric cancer. Gastrointest Endosc 2004;60:242-245.

15. Gotoda T, Yanagisawa A, Sasako M, Ono H, Nakanishi Y, Shimoda $\mathrm{T}$, et al. Incidence of lymph node metastasis from early gastric cancer: estimation with a large number of cases at two large centers. Gastric Cancer 2000;3:219-225.

16. Soetikno R, Kaltenbach T, Yeh R, Gotoda T. Endoscopic mucosal resection for early cancers of the upper gastrointestinal tract. J Clin Oncol 2005;23:4490-4498.

17. Kwak CS, Lee HK, Cho SJ, Yang HK, Lee KU, Choe KJ, et al. Analysis of clinicopathological factors associated with lymph node metastasis in early gastric cancer: review of 2137 cases. J Korean Cancer Assoc 2000;32:674-681.

18. Ye BD, Kim SG, Lee JY, Kim JS, Yang HK, Kim WH, et al. Predictive factors for lymph node metastasis and endoscopic treatment strategies for undifferentiated early gastric cancer. J Gastroenterol Hepatol 2008;23:46-50.

19. Gotoda T. A large endoscopic resection by endoscopic submucosal dissection procedure for early gastric cancer. Clin Gastroenterol Hepatol 2005;3(7 Suppl 1):S71-73.

20. Yokota T, Ishiyama S, Saito T, Teshima S, Narushima Y, Murata $\mathrm{K}$, et al. Lymph node metastasis as a significant prognostic factor in gastric cancer: a multiple logistic regression analysis. Scand J Gastroenterol 2004;39:380-384.

21. Kojima T, Parra-blanco A, Takahashi H, Fujita R. Outcome of endoscopic mucosal resection for early gastric cancer: review of the Japanese literature. Gastrointest Endosc 1998;48:550554.

22. Choi IJ, Kim CG, Chang HJ, Kim SG, Kook MC, Bae JM. The learning curve for EMR with circumferential mucosal incision in treating intramucosal gastric neoplasm. Gastrointest Endosc 2005;62:860-865.

23. Kim JJ, Lee JH, Jung HY, Lee GH, Cho JY, Ryu CB, et al. EMR for early gastric cancer in Korea: a multicenter retrospective study. Gastrointest Endosc 2007;66:693-700. 
24. Chung IK, Lee JH, Lee SH, Kim SJ, Cho JY, Cho WY, et al. Therapeutic outcomes in 1000 cases of endoscopic submucosal dissection for early gastric neoplasms: Korean ESD Study
Group multicenter study. Gastrointest Endosc 2009;69:12281235. 